\title{
ADVANCES IN STUDSVIK'S SYSTEM FOR SPENT FUEL ANALYSES
}

\author{
Teodosi Simeonov ${ }^{1}$ and Charles Wemple ${ }^{2}$ \\ ${ }^{1}$ Studsvik Scandpower Inc \\ 10 Langley Rd, Newton, MA-02459, USA \\ ${ }^{2}$ Studsvik Scandpower Inc \\ 1070 Riverwalk Drive, Idaho Falls, ID-83402, USA \\ teodosi.simeonov@studsvik.com, charles.wemple@studsvik.com
}

\begin{abstract}
Studsvik's approach to spent nuclear fuel analyses combines isotopic concentrations, fluxes, and cross-sections, calculated by the CASMO5 neutron transport and depletion code, with irradiation history data from the SIMULATE5 reactor core simulator and tabulated isotopic decay data. These data sources are used and processed by the SNF code to compute the spent nuclear fuel characteristics. Recent advances in the system, including cross-sections and decay data from ENDF/B-VIII.R0, are presented in this paper, together with validation results against decay heat power and isotopic compositions measurements. Measurements conducted at the Swedish interim storage facility, CLAB, are used for validation of the decay heat power, while comparisons to the results of the international program ARIANE are used to demonstrate the capability of CMS5/SNF to accurately predict isotopic compositions. The paper shows the results calculated with ENDF/B-VIII.R0, and the effect on the spent fuel characteristics is evaluated by comparisons to the earlier ENDF/B-VII.R1 results.
\end{abstract}

KEYWORDS: SNF, ENDF, CLAB, ARIANE

\section{INTRODUCTION}

Studsvik's approach to spent nuclear fuel analyses combines isotopic concentrations, fluxes, and crosssections, calculated by the neutron transport and depletion code CASMO5 [1], with irradiation history data from the reactor core simulator SIMULATE5 [2] and tabulated isotopic decay data. These data sources are used and processed by the SNF code [3,4] to compute the basic spent nuclear fuel characteristics: isotopic concentrations; radioactivity; decay heat power; photon sources and spectra; neutron source and spectra from spontaneous fission; neutron source and spectra from $(\alpha, n)$ reactions.

This code system is fully integrated with Studsvik's Core Monitoring System (CMS5) and implicitly employs the three-dimensional (3D) discretization of the assemblies in the reactor core. Designed and implemented as a production tool, it provides comprehensive results per axial node of a fuel assembly or a fuel pin. In addition to the basic spent fuel characteristics, the SNF code is supplied with various optional modules intended to support and facilitate data preparation for analyses related to handling, transportation and storage of spent fuel, including accident analyses, burnup credit in criticality safety evaluations, and dry cask loading scenarios. The decay heat power, computed by the summation method, is complemented 
by two standards for decay heat power in light water reactors: ANSI/ANS-5.1-2014 [5] and DIN-254631/2-2014 [6], implemented as integrated methodology or as stand-alone applications.

The latest set of decay data implemented in the SNF code is based on ENDF/B-VII.R1 [7]. With the release of ENDF/B-VIII.R0 [8] and following its implementation [9] in CASMO5, a new decay data set based on ENDF/B-VIII.R0 was generated. Its application to two validation benchmarks is presented in this work, along with a brief description of the methodology.

\section{METHODOLOGY}

The cross-section library, generated by the lattice physics code CASMO5, provides isotopic concentrations tabulated by exposure, moderator density history, control rod history, fuel temperature, and boron history. The nodewise exposure and accumulated history parameters, obtained from qualified operational reactor data or code simulation (SIMULATE5), are used as entry points in the interpolation routines and, with the power history model, are used to compute the end-of-life (EOL) isotopic concentration. The fuel assembly is divided into axial nodes (index: $\mathrm{K}$ ) that may be further divided into sub-nodes $(\mathrm{N})$. A sub-node is characterized by its associated lattice type (L). The concentration $C_{\text {base }}$ of a given isotope $(\mathrm{J})$ in sub-node $(\mathrm{N})$ of node $(\mathrm{K})$ is calculated as:

$$
C_{b a s e}^{J, K, N}=C_{t a b}^{J, L}(E)+\sum_{h \in H} \Delta C_{t a b}^{J, L, h}(E) * \Delta H_{h}
$$

where:

$C_{\text {tab }}^{J, L}(E)$ is the concentration $(\mathrm{g} / \mathrm{t})$ of isotope $\mathrm{J}$ in lattice type $\mathrm{L}$ at exposure $\mathrm{E}$;

$\Delta C_{\text {tab }}^{J, L, h}(E)$ is the history-differential (difference between base and alternate depletion histories) concentration of isotope $\mathrm{J}$ in lattice type $\mathrm{L}$ at exposure $\mathrm{E}$;

$\Delta H_{h}$ is a nodal history effect (moderator density, control, boron, void, fuel temperature, etc.).

In this equation, all concentrations are obtained by interpolation in two-dimensional tables for lattice type $\mathrm{L}$ to the nodal exposure $\mathrm{E}$. The nodal concentrations, $C_{b a s e}^{J, K}$, are obtained by a weighted average over the sub-nodes in each node. Further, the individual isotope concentrations are affected by the nodal power variations, the effect of which can be significant for many isotopes. SNF makes use of the nodal power histories (from the 3D core simulator) to apply "power history correction factors", $c_{P H I S T}^{J, K}$ :

$$
C_{E O L}^{J, K}=c_{P H I S T}^{J, K} * C_{\text {base }}^{J, K}
$$

to the nodal concentrations. The power history correction factor for isotope $\mathrm{J}$ in node $\mathrm{K}$ with burnup $\mathrm{E}$ is defined as the ratio of the final concentration, $C_{J}$, computed with the actual power history, to the reference concentration, $C_{J}^{\text {ref }}$, computed with the reference power level at the same burnup.

The EOL isotopic concentrations are then applied to the decay chains resolved by Bateman system. The Bateman system is solved analytically by a method from [10] to obtain the final concentration, $C_{t}^{J, K}$, at decay time t. The decay chains are built exactly as defined by the parent-daughter information from ENDF, which allows all other parameters (such as recoverable energies, decay constants, and emission spectra) to be applied implicitly. With the final isotopic concentrations, it is straightforward to compute the disintegration rates at cooling time $t$, and the recoverable energy is computed by:

$$
Q^{J, K}(t)=\sum_{m=\alpha, \beta, \gamma} Q_{m}^{J, K} * R^{J, K}(t)
$$


where:

$R^{J, K}(t)$ is the disintegration rate of isotope $\mathrm{J}$ in node $\mathrm{K}$, after time $\mathrm{t}$;

$Q_{m}^{J, K}$ is the average recoverable energy per disintegration for particle type $\mathrm{m}$.

\section{DECAY DATA}

The SNF library includes basic data, such as decay constants, atomic masses, and nuclide transmutation chains; radiation emission spectra for photons from radioactive decay, $(\alpha, n)$ reactions, bremsstrahlung, and spontaneous fission; electrons and alpha particles from radioactive decay; neutrons from radioactive decay, spontaneous fission, and $(\alpha, n)$ reactions; decay heat production; and electro-atomic interaction data for bremsstrahlung production. These data are compiled from fundamental (ENDF, ENSDF [11], TENDL $[12,13]$ ) and processed (ESTAR and ASTAR [14]) sources. For consistency with CASMO5, ENDF/BVII.R1 data are complemented with data from TENDL-2012 [12], and the ENDF/B-VIII.R0 data are complemented with data from TENDL-2017 [13]. The evaluation and validation procedure of the decay data implemented in the SNF library is reported elsewhere [15].

The basic decay data set per isotope - half-life, atomic mass, decay modes and branching ratios, Q-values, and daughter isotopes - is entirely derived from ENDF, as are the discrete emission spectra for $\alpha, \gamma$, and $\mathrm{x}$-rays. The uncertainty of line-energies for the discrete spectra is provided by ENDF. When populating the photons in the user-defined energy groups, the intensity of a given line may be split equally between the adjacent groups if the group-boundary falls within the corresponding line-uncertainty. For the continuum spectra for prompt photons emitted during spontaneous fission and $\alpha$-decay, empirical correlations from [16] are adopted.

The $(\alpha, n)$ and $(\alpha, \gamma)$ reaction data are processed from TENDL by NJOY-2012 [17], with the alpha particle stopping powers for the elements, including compounds and mixtures, derived from ASTAR. The TENDL data for the oxygen isotopes ${ }^{17} \mathrm{O}$ and ${ }^{18} \mathrm{O}$ is complemented by $(\alpha, n)$ cross-sections from Perry and Wilson [18]. The approach used for these isotopes was to rescale the neutron resonance data of Perry and Wilson to match the TENDL data at the upper energy of the resonance range $\left(5.404 \mathrm{MeV}\right.$ for ${ }^{17} \mathrm{O}$ and $5.18 \mathrm{MeV}$ for ${ }^{18} \mathrm{O}$ ); the rescaling increased the cross-sections below these energies by $\sim 25 \%$ and $\sim 4 \%$, respectively. This allowed the cross-section representation to be extended to the upper limit of the SNF $\alpha$-decay data $(\sim 12 \mathrm{MeV})$. The photon production data were not rescaled. Compared to TENDL-2012, the TENDL-2017 based $(\alpha, n)$-yields are in average about $2 \%$ smaller.

The continuum spectra for electrons and positrons were calculated by the method of Stamatelatos and England [19], coupled with the Fermi function approximation of Schenter and Vogel [20], with the spectrum endpoint energies provided in the ENDF decay sub-library. The external bremsstrahlung crosssections and production kernels were processed from the ENDF electron sub-library, while the electron stopping power data were calculated with the ESTAR application.

\section{VALIDATION RESULTS}

\subsection{CLAB decay heat power measurements}

The measurements were performed during 2003-2004 by SKB in the interim storage facility CLAB in Sweden [21]. Assemblies of nine different designs were measured, with exposures ranging from 20 $\mathrm{GWd} / \mathrm{tHM}$ to $51 \mathrm{GWd} / \mathrm{tHM}$ and cooling times from 10 years to 22 years. The decay heat measurements were performed by means of an electrically calibrated calorimeter submerged in water. The measured decay heat powers have been corrected for the fraction of the released gamma heat absorbed outside the 
calorimeter tank. The design goal for the measurement uncertainty is established to be less than $\pm 2 \%$. Table I and Figure 1 present C/E results calculated with the two sets of decay data - E7R1 and E8R0.

Table I. C/E comparison between CMS5/SNF and CLAB measurements.

\begin{tabular}{|c|c|c|c|c|c|c|c|c|c|c|c|}
\hline $\begin{array}{c}\text { Assem } \\
\text { ID }\end{array}$ & $\begin{array}{c}\text { Meas. } \\
\text { W }\end{array}$ & $\begin{array}{c}\text { E7R1 } \\
\text { C/E }\end{array}$ & $\begin{array}{c}\text { E8R0 } \\
\text { C/E }\end{array}$ & $\begin{array}{c}\text { Assem } \\
\text { ID }\end{array}$ & $\begin{array}{c}\text { Meas. } \\
\text { W }\end{array}$ & $\begin{array}{c}\text { E7R1 } \\
\text { C/E }\end{array}$ & $\begin{array}{c}\text { E8R0 } \\
\text { C/E }\end{array}$ & $\begin{array}{l}\text { Assem } \\
\text { ID }\end{array}$ & $\begin{array}{c}\text { Meas. } \\
\text { W }\end{array}$ & $\begin{array}{c}\text { E7R1 } \\
\text { C/E }\end{array}$ & $\begin{array}{c}\text { E8R0 } \\
\text { C/E }\end{array}$ \\
\hline$C 01$ & 415.8 & 1.011 & 1.006 & OC9 & 491.2 & 1.025 & 1.020 & 14076 & 240.3 & 0.983 & 0.981 \\
\hline C12 & 410.3 & 1.015 & 1.010 & $O E 2$ & 587.9 & 1.002 & 0.997 & 3838 & 126.4 & 1.016 & 1.013 \\
\hline C2O & 426.6 & 1.009 & 1.005 & $O E 6$ & 487.8 & 1.006 & 1.003 & KU0100 & 185.3 & 0.971 & 0.969 \\
\hline$C 42$ & 445.3 & 0.980 & 0.976 & $1 C 2$ & 417.7 & 1.020 & 1.016 & KU0269 & 192.7 & 0.973 & 0.971 \\
\hline$D 27$ & 456.1 & 0.991 & 0.987 & $1 C 5$ & 499.2 & 1.010 & 1.005 & $K U 0278$ & 195.4 & 0.968 & 0.966 \\
\hline D38 & 442.3 & 1.010 & 1.007 & $1 E 5$ & 468.8 & 0.999 & 0.997 & KU0282 & 218.5 & 0.975 & 0.972 \\
\hline$E 38$ & 375.3 & 0.994 & 0.993 & $2 A 5$ & 233.8 & 1.033 & 1.029 & 5535 & 84.6 & 1.052 & 1.050 \\
\hline$E 40$ & 381.3 & 0.989 & 0.985 & $2 C 2$ & 466.5 & 1.019 & 1.014 & 11494 & 166.0 & 0.991 & 0.989 \\
\hline F14 & 381.8 & 0.995 & 0.993 & $3 C 1$ & 470.2 & 1.009 & 1.005 & 11495 & 167.6 & 0.983 & 0.981 \\
\hline F21 & 420.9 & 0.993 & 0.990 & $3 C 4$ & 497.3 & 1.005 & 1.000 & 13775 & 178.4 & 0.996 & 0.994 \\
\hline F25 & 396.7 & 1.005 & 1.002 & $3 C 5$ & 501.4 & 1.006 & 1.001 & 13847 & 169.9 & 1.009 & 1.007 \\
\hline F32 & 692.0 & 1.008 & 1.000 & $3 C 9$ & 468.4 & 1.012 & 1.008 & 13848 & 170.7 & 1.004 & 1.002 \\
\hline G11 & 416.4 & 0.988 & 0.986 & $4 C 4$ & 422.0 & 1.009 & 1.005 & 12684 & 282.7 & 0.987 & 0.985 \\
\hline G23 & 420.6 & 0.995 & 0.993 & $4 C 7$ & 498.7 & 1.011 & 1.006 & 12078 & 120.2 & 1.020 & 1.018 \\
\hline 109 & 507.9 & 1.016 & 1.013 & $5 A 3$ & 239.3 & 1.007 & 1.003 & 13628 & 194.0 & 1.014 & 1.012 \\
\hline$I 20$ & 403.5 & 1.001 & 0.999 & $5 A 3$ & 230.6 & 1.027 & 1.023 & 13630 & 235.7 & 1.000 & 0.998 \\
\hline$I 24$ & 410.1 & 0.993 & 0.991 & $5 F 2$ & 714.1 & 0.993 & 0.988 & & & & \\
\hline$I 25$ & 445.8 & 0.994 & 0.991 & & & & & & & & \\
\hline
\end{tabular}

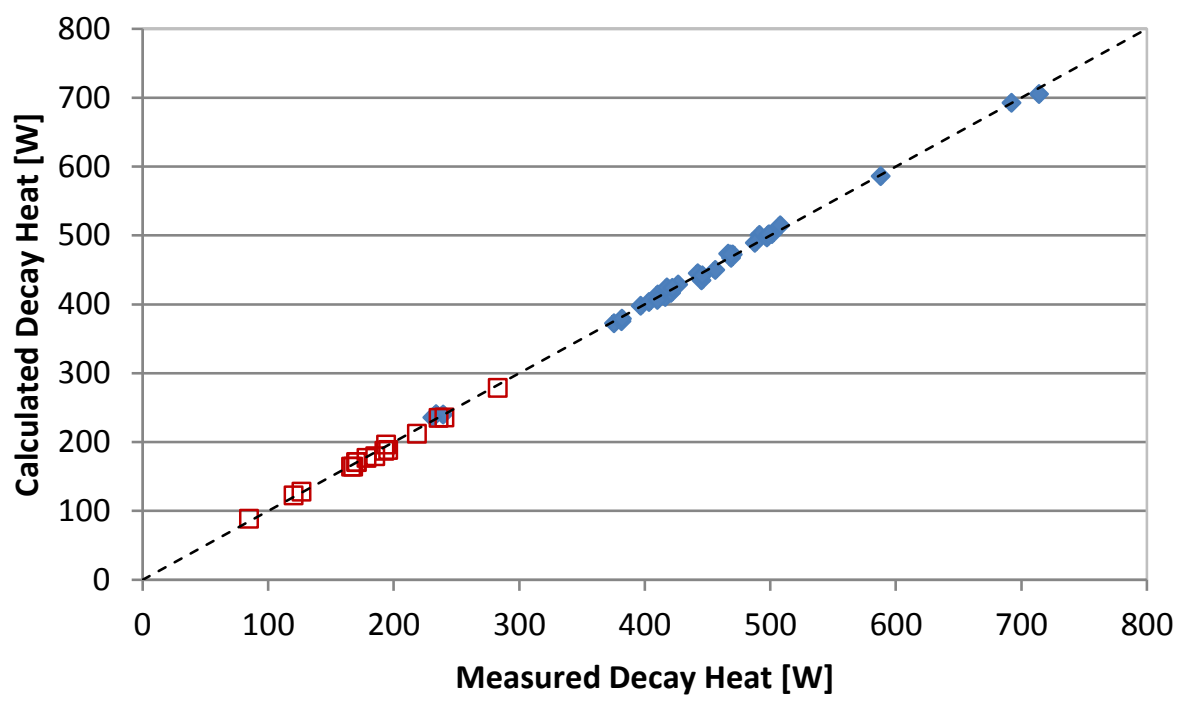

Figure 1. Comparison of C/E between CLAB measurements and CMS5/SNF (BWR assemblies red squares; PWR assemblies - blue diamonds).

The overall effect of E8R0 on the decay heat powers, presented in Table II, is considered very small as compared to E7R1. The average deviation decreases by about $0.4 \%$ with effectively identical standard deviation. Overall, the calculated decay heat powers are in very good agreement with the experimental results. The observed average deviation of $0.1-0.3 \%$ along with the standard deviation of $\sim 1.7 \%$ demonstrates the ability of Studsvik's SNF system to reliably predict the assembly decay heat power for 
assemblies irradiated in BWR or PWR. A deviation below the measurement uncertainty goal of $2.0 \%$ is observed for 40 out of 51 measurements, and 49 assemblies are within $3 \%$.

Table II. Comparison summary of C/E between CMS5/SNF and CLAB measurements.

\begin{tabular}{|l|c|c|c|c|c|}
\hline $\begin{array}{c}\text { Lattice } \\
\text { Type }\end{array}$ & $\begin{array}{c}\text { \# of meas. } \\
\text { assemblies }\end{array}$ & \multicolumn{2}{|c|}{$\begin{array}{c}\text { ENDF/B-VII.R1 } \\
\text { Decay heat power C/E }\end{array}$} & \multicolumn{2}{c|}{$\begin{array}{c}\text { ENDF/B-VIII.R0 } \\
\text { Decay heat power C/E }\end{array}$} \\
\hline & & Average & $\mathbf{2 \sigma} \mathbf{( \% )}$ & Average & $\mathbf{2 \sigma} \mathbf{( \% )}$ \\
\hline pwr15x15 & 18 & 0.999 & 2.0 & 0.996 & 2.0 \\
\hline pwr17x17 & 17 & 1.014 & 2.2 & 1.007 & 2.0 \\
\hline bwr & 16 & 0.997 & 4.4 & 0.994 & 4.4 \\
\hline All & $\mathbf{5 1}$ & $\mathbf{1 . 0 0 3}$ & $\mathbf{3 . 4}$ & $\mathbf{0 . 9 9 9}$ & $\mathbf{3 . 2}$ \\
\hline
\end{tabular}

The BWR results are slightly more dispersed, with standard deviation $2.2 \%$, compared to $\sim 1 \%$ standard deviation for the PWRs. It should be noted that the set of BWR assemblies consists of 6 different assembly designs irradiated in 6 different reactors. However, the number of assemblies per type is insufficient to make confident conclusions about dependencies on the assembly type or on reactor type.

\subsection{ARIANE, PIE of MOX fuel irradiated in PWR}

The ARIANE program [22] (Actinides Research In A Nuclear Element) is an experimental program designed to improve the evaluation and prediction of actinides and fission products in MOX and UOX fuel elements. The program was conducted between 1995 and 2001, following irradiation of 10 fuel rods (17 samples, MOX and UOX) in three reactors - 2 PWRs (Beznau and Gösgen) and one BWR (Dodewaard). The PIE was performed independently in three laboratories - Paul Scherrer Institute (PSI) (Switzerland), SCK.CEN (Belgium), and ITU (Germany) - and the measurements were cross-checked for verification.

Comparisons of calculated vs. experimental results (C/E) for samples BM1 and BM5 are presented in this paper. The two samples were irradiated to about $46.5 \mathrm{GWd} / \mathrm{tHM}$ and $56.5 \mathrm{GWd} / \mathrm{tHM}$ in two different assemblies at Beznau NPP during normal operation between cycles 18 and 22. The results presented in this work are obtained by applying the irradiation histories from SIMULATE5 [23], two sets of crosssection data from CASMO5, and two sets of decay data based on E7R1 and E8R0, respectively.

The evaluation of the fuel samples is based on data generated for the corresponding fuel rods. The nuclear data required for the analyses of the selected fuel rod are computed by CASMO5 along with the nodal data for SIMULATE5 and tabulated by CMSLINK5. The rod exposures are computed by the pin-power reconstruction model in SIMULATE5, following detailed simulation of the reactor operation history [23]. The isotopic concentrations are computed for the axial node corresponding to where the samples were cut.

The experimental values recommended for code validation were subjected to cross-check analyses and validated either by combining the two measurements Equation 4, or as a unique recommended value. The $\mathrm{C} / \mathrm{E}$ comparison for samples BM1 and BM5 is shown in Table III.

$$
x_{r}=\frac{\frac{x_{1}}{\sigma_{x_{1}}^{2}}+\frac{x_{2}}{\sigma_{x_{2}}^{2}}}{\frac{1}{\sigma_{x_{1}}^{2}}+\frac{1}{\sigma_{x_{2}}^{2}}} \text { with } \sigma_{x_{r}}^{2}=\frac{1}{\sigma_{x_{1}}^{2}}+\frac{1}{\sigma_{x_{2}}^{2}}
$$


Table III. C/E comparison between CMS5/SNF calculation and BM1 and BM5 samples.

\begin{tabular}{|c|c|c|c|c|c|c|c|c|c|c|}
\hline \multirow[b]{2}{*}{ Nuclide } & \multicolumn{4}{|c|}{ BM1 } & \multirow[b]{2}{*}{ Note } & \multicolumn{5}{|c|}{ BM5 } \\
\hline & $\mathrm{mg} / \mathrm{g}$ fuel & E7R1 & E8R0 & $2 \sigma, \%$ & & $\mathrm{mg} / \mathrm{g}$ fuel & E7R1 & E8R0 & $2 \sigma, \%$ & Note \\
\hline U-234 & 7.81E-02 & 0.995 & 0.990 & 7.85 & & 4.94E-02 & 0.982 & 0.975 & 9.19 & \\
\hline U-235 & $8.28 \mathrm{E}-01$ & 1.002 & 0.983 & 1.99 & & $5.86 \mathrm{E}-01$ & 1.034 & 1.004 & 2.05 & \\
\hline U-236 & $2.56 \mathrm{E}-01$ & 0.957 & 0.969 & 4.14 & & $2.69 \mathrm{E}-01$ & 0.964 & 0.975 & 4.54 & \\
\hline U-238 & $8.07 \mathrm{E}+02$ & 0.993 & 0.993 & 0.45 & & $7.98 \mathrm{E}+02$ & 0.995 & 0.995 & 0.45 & \\
\hline Np-237 & $1.50 \mathrm{E}-01$ & 1.093 & 1.077 & 12.07 & & $1.75 \mathrm{E}-01$ & 1.016 & 1.002 & 0.43 & \\
\hline Pu-238 & $1.11 \mathrm{E}+00$ & 0.989 & 0.983 & 3.05 & & $9.95 \mathrm{E}-01$ & 1.011 & 1.002 & 3.05 & \\
\hline Pu-239 & $1.19 \mathrm{E}+01$ & 1.055 & 1.040 & 0.56 & & $9.80 \mathrm{E}+00$ & 1.070 & 1.049 & 0.57 & \\
\hline Pu-240 & $1.18 \mathrm{E}+01$ & 0.992 & 1.004 & 0.56 & & $1.01 \mathrm{E}+01$ & 0.983 & 0.996 & 0.57 & \\
\hline Pu-241 & $6.06 \mathrm{E}+00$ & 1.020 & 1.005 & 0.56 & & $5.39 \mathrm{E}+00$ & 1.013 & 0.997 & 0.57 & \\
\hline Pu-242 & $3.88 \mathrm{E}+00$ & 0.990 & 0.986 & 0.56 & & $3.67 \mathrm{E}+00$ & 0.967 & 0.962 & 0.57 & \\
\hline Pu-244 & $6.85 \mathrm{E}-04$ & 0.539 & 0.554 & 49.93 & & $1.00 \mathrm{E}-03$ & 0.449 & 0.461 & 50.10 & \\
\hline Am-241 & $2.17 \mathrm{E}+00$ & 1.043 & 1.027 & 2.54 & & $1.12 \mathrm{E}+00$ & 1.184 & 1.165 & 2.78 & \\
\hline Am-242m & $1.48 \mathrm{E}-02$ & 1.051 & 1.031 & 9.46 & & $1.06 \mathrm{E}-02$ & 1.228 & 1.198 & 4.78 & \\
\hline Am-243 & $9.87 \mathrm{E}-01$ & 0.976 & 0.971 & 3.51 & & $9.09 \mathrm{E}-01$ & 1.045 & 1.038 & 0.28 & \\
\hline Cm-242 & $1.70 \mathrm{E}-01$ & 0.878 & 0.868 & 3.49 & & $1.56 \mathrm{E}-01$ & 0.869 & 0.857 & 3.46 & \\
\hline Cm-243 & 8.74E-03 & 0.938 & 0.928 & 6.45 & & 7.42E-03 & 1.104 & 1.090 & 10.59 & \\
\hline Cm-244 & $6.15 \mathrm{E}-01$ & 1.009 & 1.007 & 1.48 & EOL & $8.13 \mathrm{E}-01$ & 0.907 & 0.903 & 2.48 & EOL \\
\hline Cm-245 & 5.99E-02 & 1.094 & 1.086 & 2.57 & & 8.96E-02 & 0.979 & 0.970 & 3.42 & \\
\hline Cm-246 & $6.52 \mathrm{E}-03$ & 0.924 & 0.928 & 3.57 & & $1.47 \mathrm{E}-02$ & 0.774 & 0.780 & 4.68 & \\
\hline Ce-144 & $2.50 \mathrm{E}-01$ & 1.033 & 1.027 & 6.88 & & $2.38 \mathrm{E}-01$ & 1.017 & 1.010 & 5.13 & \\
\hline Nd-142 & $1.72 \mathrm{E}-02$ & 1.030 & 1.032 & 6.98 & & $2.91 \mathrm{E}-02$ & 0.992 & 0.995 & 7.01 & \\
\hline Nd-143 & $9.00 \mathrm{E}-01$ & 1.008 & 1.004 & 0.56 & & $1.04 \mathrm{E}+00$ & 0.990 & 0.986 & 0.56 & \\
\hline Nd-144 & $1.19 \mathrm{E}+00$ & 0.992 & 0.991 & 0.56 & & $1.54 \mathrm{E}+00$ & 0.959 & 0.959 & 0.56 & \\
\hline Nd-145 & 7.01E-01 & 1.007 & 1.005 & 0.56 & & $8.40 \mathrm{E}-01$ & 0.982 & 0.979 & 0.56 & \\
\hline Nd-146 & 7.40E-01 & 1.009 & 1.008 & 0.56 & & $9.58 \mathrm{E}-01$ & 0.976 & 0.974 & 0.56 & \\
\hline Nd-148 & 4.43E-01 & 1.012 & 1.011 & 0.56 & & $5.49 \mathrm{E}-01$ & 0.984 & 0.984 & 0.56 & \\
\hline Nd-150 & $2.65 \mathrm{E}-01$ & 1.015 & 1.013 & 0.58 & & $3.28 \mathrm{E}-01$ & 0.988 & 0.987 & 0.58 & \\
\hline Pm-147 & $1.85 \mathrm{E}-01$ & 0.975 & 0.970 & 2.91 & & $1.77 \mathrm{E}-01$ & 0.977 & 0.973 & 10.45 & \\
\hline Sm-147 & $2.65 \mathrm{E}-01$ & 0.972 & 0.969 & 1.05 & & $2.35 \mathrm{E}-01$ & 1.003 & 1.000 & 0.61 & last date \\
\hline Sm-148 & $1.89 \mathrm{E}-01$ & 0.970 & 0.977 & 0.63 & & $2.74 \mathrm{E}-01$ & 0.960 & 0.966 & 0.59 & analyses \\
\hline Sm-149 & $5.03 \mathrm{E}-03$ & 1.084 & 1.062 & 2.05 & & $4.85 \mathrm{E}-03$ & 0.998 & 0.974 & 9.25 & analyses \\
\hline Sm-150 & $3.62 \mathrm{E}-01$ & 0.996 & 0.993 & 0.64 & & 4.37E-01 & 0.991 & 0.986 & 0.60 & analyses \\
\hline Sm-151 & $2.47 \mathrm{E}-02$ & 1.001 & 0.981 & 8.26 & & $2.27 \mathrm{E}-02$ & 1.047 & 1.021 & 0.77 & EOL \\
\hline Sm-152 & $1.64 \mathrm{E}-01$ & 0.928 & 0.925 & 0.63 & & $1.60 \mathrm{E}-01$ & 0.979 & 0.975 & 0.61 & analyses \\
\hline Sm-154 & 7.95E-02 & 0.966 & 0.962 & 0.65 & & 8.97E-02 & 1.030 & 1.028 & 0.63 & analyses \\
\hline Eu-151 & $1.27 \mathrm{E}-03$ & 0.985 & 0.965 & 3.31 & & 7.94E-04 & 0.784 & 0.764 & 2.07 & \\
\hline Eu-153 & $1.96 \mathrm{E}-01$ & 0.980 & 0.977 & 0.66 & & $2.32 \mathrm{E}-01$ & 0.961 & 0.959 & 0.63 & \\
\hline Eu-154 & $5.38 \mathrm{E}-02$ & 1.050 & 1.011 & 2.47 & EOL & $6.65 \mathrm{E}-02$ & 1.076 & 1.027 & 1.94 & \\
\hline Eu-155 & $1.77 \mathrm{E}-02$ & 0.842 & 0.855 & 3.84 & EOL & $1.94 \mathrm{E}-02$ & 0.976 & 0.987 & 4.33 & \\
\hline Gd-154 & $2.71 \mathrm{E}-02$ & 1.078 & 1.041 & 2.97 & PSI & $2.76 \mathrm{E}-02$ & 1.007 & 0.968 & 3.62 & PSI \\
\hline Gd-155 & $9.36 \mathrm{E}-03$ & 0.988 & 1.004 & 2.67 & & 7.44E-03 & 0.981 & 0.991 & 2.00 & \\
\hline Gd-156 & $1.53 \mathrm{E}-01$ & 0.940 & 0.952 & 1.37 & PSI & $2.60 \mathrm{E}-01$ & 0.860 & 0.874 & 3.10 & PSI \\
\hline Gd-158 & $4.15 \mathrm{E}-02$ & 1.067 & 1.067 & 2.21 & PSI & $5.75 \mathrm{E}-02$ & 1.016 & 1.018 & 3.58 & PSI \\
\hline Gd-160 & $3.36 \mathrm{E}-03$ & 0.977 & 0.974 & 6.88 & PSI & $4.31 \mathrm{E}-03$ & 0.921 & 0.917 & 4.97 & PSI \\
\hline Sr-90 & $3.43 \mathrm{E}-01$ & 0.920 & 0.920 & 0.83 & & $3.96 \mathrm{E}-01$ & 0.948 & 0.949 & 9.17 & \\
\hline Mo-95 & $6.06 \mathrm{E}-01$ & 1.207 & 1.204 & 3.75 & & $9.31 \mathrm{E}-01$ & 0.932 & 0.931 & 3.61 & \\
\hline Tc-99 & $5.74 \mathrm{E}-01$ & 1.613 & 1.608 & 2.80 & & $1.07 \mathrm{E}+00$ & 1.005 & 1.004 & 4.40 & \\
\hline Ru-101 & $5.74 \mathrm{E}-01$ & 1.748 & 1.743 & 2.80 & & $1.23 \mathrm{E}+00$ & 0.965 & 0.964 & 4.14 & analyses \\
\hline Ru-106 & $1.38 \mathrm{E}-01$ & 2.011 & 1.996 & 3.33 & & $2.29 \mathrm{E}-01$ & 1.153 & 1.146 & 7.62 & EOL \\
\hline Rh-103 & $4.41 \mathrm{E}-01$ & 2.032 & 2.024 & 7.78 & & $9.91 \mathrm{E}-01$ & 0.989 & 0.984 & 2.57 & analyses \\
\hline Ag-109 & 8.70E-02 & 1.207 & 1.203 & 1.92 & & 1.49E-01 & 1.130 & 0.825 & 17.33 & analyses \\
\hline Sb-125 & $6.73 \mathrm{E}-03$ & 1.712 & 1.705 & 5.99 & & $8.21 \mathrm{E}-03$ & 1.446 & 1.442 & 3.69 & EOL \\
\hline I-129 & & & & & & $2.24 \mathrm{E}-01$ & 1.371 & 1.368 & 11.25 & \\
\hline
\end{tabular}




\begin{tabular}{|c|rrrrc|cccc|}
\hline Cs-133 & $1.34 \mathrm{E}+00$ & 1.021 & 1.020 & 1.79 & analyses & $1.55 \mathrm{E}+00$ & 1.016 & 1.014 & 2.14 \\
Cs-134 & $1.53 \mathrm{E}-01$ & 0.945 & 0.943 & 1.86 & EOL & $2.06 \mathrm{E}-01$ & 0.940 & 0.939 & 2.30 \\
Cs-135 & $8.58 \mathrm{E}-01$ & 1.029 & 1.014 & 1.80 & analyses & $1.06 \mathrm{E}+00$ & 0.980 & 0.964 & 2.08 \\
Cs-137 & $1.52 \mathrm{E}+00$ & 1.005 & 1.003 & 1.77 & EOL & $1.82 \mathrm{E}+00$ & 0.998 & 0.997 & 2.16 \\
\hline
\end{tabular}

The cross-check analyses did not provide a recommended value for several isotopes. Instead, the value for the following isotopes was marked as "maintained but no recommendation":

BM1: ${ }^{244} \mathrm{Cm},{ }^{154} \mathrm{Eu},{ }^{155} \mathrm{Eu},{ }^{133} \mathrm{Cs},{ }^{134} \mathrm{Cs},{ }^{135} \mathrm{Cs}$ and ${ }^{137} \mathrm{Cs}$

BM5: ${ }^{244} \mathrm{Cm},{ }^{147} \mathrm{Sm},{ }^{148} \mathrm{Sm},{ }^{149} \mathrm{Sm},{ }^{150} \mathrm{Sm},{ }^{151} \mathrm{Sm},{ }^{152} \mathrm{Sm},{ }^{154} \mathrm{Sm},{ }^{101} \mathrm{Ru},{ }^{106} \mathrm{Ru},{ }^{103} \mathrm{Rh},{ }^{109} \mathrm{Ag},{ }^{125} \mathrm{Sb}$

The above isotopes were included in the analyses presented here with their experimental value and uncertainties defined by Equation 4. The state of comparisons of those isotopes is notified in column "Note" in Table III as provided in the benchmark specification: EOL - end of life; analyses - at the time of analyses; last date - at last date available. Four gadolinium isotopes $-{ }^{154} \mathrm{Gd},{ }^{156} \mathrm{Gd},{ }^{158} \mathrm{Gd}$ and ${ }^{160} \mathrm{Gd}-$ were measured only by PSI (hence with "no maintained value") were included and marked as PSI, which stands for "PSI measurement at the time of analyses".

In general, the effect of ENDF/B-VIII.R0 on the prediction of the selected isotopes, although small in most cases, is in the direction of improving the agreement. The overall tendency of decreasing the calculated concentrations is attributed to small variations in the irradiation history conditions for the reactor cores simulated by cross-sections based on E7R1 and E8R0. Although most changes are within $1 \%$, noticeable improvement can be observed in:

$$
\begin{aligned}
& \mathrm{BM} 1:{ }^{239} \mathrm{Pu}(1.5 \%),{ }^{154} \mathrm{Eu}(3.7 \%),{ }^{154-156} \mathrm{Gd}(2-3.5 \%) \\
& \text { BM5 : }{ }^{235} \mathrm{U}(3 \%),{ }^{239} \mathrm{Pu}(2 \%),{ }^{151} \mathrm{Sm}(2.4 \%),{ }^{154} \mathrm{Eu}(4.5 \%)
\end{aligned}
$$

The calculations and the measurements are generally in very good agreement with 49 out of 57 isotopes within $10 \%$. Excellent agreement can be observed for the uranium and plutonium isotopes, except ${ }^{244} \mathrm{Pu}$. An underestimation of $\sim 50 \%$ and $\sim 12 \%$ is observed in ${ }^{244} \mathrm{Pu}$ and ${ }^{242} \mathrm{Cm}$, respectively, for both samples; ${ }^{246} \mathrm{Cm}$ is underpredicted by $\sim 22 \%$ for BM5, but within $10 \%$ for BM1. A similar, but reverse, result is observed in ${ }^{241} \mathrm{Am}$ and ${ }^{242 \mathrm{~m}} \mathrm{Am}$ - both are overpredicted for BM5 by $\sim 18 \%$ and $\sim 22 \%$, respectively. The measurement uncertainty of ${ }^{244} \mathrm{Pu}$ is $\sim 50 \%$ and quite comparable to the observed deviation. However, given the good agreement in ${ }^{241} \mathrm{Pu}(\sim 1.2 \%)$ and the underprediction in ${ }^{242} \mathrm{Cm}$ and ${ }^{246} \mathrm{Cm}$, the overprediction in the two americium isotopes for BM5 is inconsistent and difficult to explain.

The prediction of the fission products - isotopes of Ce, Nd, Pm, Eu (except ${ }^{151} \mathrm{Eu}$ for BM5), Gd, and Cs are in excellent agreement. It is observed that for BM5, most of the traditionally difficult-to-measure metallic fission products are also in excellent agreement: ${ }^{90} \mathrm{Sr},{ }^{95} \mathrm{Mo},{ }^{99} \mathrm{Tc},{ }^{101} \mathrm{Ru}$, and ${ }^{103} \mathrm{Rh}$. The overpredictions observed in the metallic fission products for BM1 are generally explained by incomplete dissolution, resulting in significant remaining residue.

\section{CONCLUSIONS}

The application of Studsvik's system for spent nuclear fuel analyses together with nuclear data libraries based on the latest release of ENDF/B-VIII.R0 is presented in this work. A comparison against decay heat powers measurements, CLAB, and the PIE program ARIANE were presented to demonstrate the applicability of E8R0 for spent fuel calculation. 


\section{REFERENCES}

1. J. Rhodes, et al., "CASMO-5 Development and Applications," Proceedings of PHYSOR-2006, Vancouver, BC, Canada. September 10-14 (2006).

2. T. Bahadir and S.-Ö. Lindhal, "Studsvik's Next Generation Nodal Code SIMULATE-5," Proc. Advances in Nuclear Fuel Management IV (ANFM IV), Hilton Head, SC, USA, April 12-15 (2009).

3. S. Børresen, "Spent Fuel Analyses based on In-Core Fuel Management Calculations," Proc. PHYSOR 2004, Chicago, Illinois, (April 25-29 2004).

4. T. Simeonov and C. Wemple, "Development in Studsvik's system for spent fuel analyses," Proc. 26th AER symposium, Helsinki, Finland, 10-14 October (2016).

5. “American National Standard for Decay Heat Power in Light Water Reactors,"ANSI/ANS-5.1 (2014)

6. "Berechnung der Zerfallsleistung der Kernbrennstoffe von Leichtwassereactoren," DIN-25463-1/2, (2014).

7. M. Chadwick, et al., "ENDF/B-VII.1 nuclear data for science and technology: Cross sections, covariances, fission product yields and decay data." Nuclear Data Sheets, 112(12), (2011).

8. D.A. Brown, et al., "ENDF/B-VIII.0: The 8th Major Release of the Nuclear Reaction Data Library with CIELO-project Cross Sections, New Standards and Thermal Scattering Data," Nuclear Data Sheets, 148, pp. 1-142 (2018).

9. R. Ferrer and J. Rhodes, "Generation and initial validation of a new CASMO5 ENDF/B-VIII.0 nuclear data library," Proc. PHYSOR-2020, Cambridge, UK, March 29-April 2 (2020).

10. R. J. J. Stamm'ler, M. J. Abbate, Methods of Steady-State Reactor Physics in Nuclear Design, Academic Press, p. 384 (1983).

11. J.K. Tuli, "Evaluated Nuclear Structure Data File," BNL-NCS-51655-01/02-Rev, BNL (2001).

12. A.J. Koning and D. Rochman, "Modern Nuclear Data Evaluation with the TALYS Code System," Nuclear Data Sheets, 113(12), p. 2841 (2012).

13. A.J. Koning, et al., "TENDL: Complete Nuclear Data Library for Innovative Nuclear Science and Technology," Nuclear Data Sheets, 155, pp. 1-55 (2019).

14. M.J. Berger, et al., "ESTAR, PSTAR, and ASTAR,”NIST, (2015) http://physics.nist.gov/Star .

15. T. Simeonov and C. Wemple, "Update and Evaluation of Decay Data for Spent Nuclear Fuel Analyses," Proc. Nuclear Data 2016, Bruges, Belgium, September (2016).

16. 18. R.W. Peele and F.C, Maienschein, "The absolute spectrum of photons emitted in coincidence with thermal-neutron fission of Uranium-235," ORNL-4457 (1970).

17. A.C. Kahler (ed.), "The NJOY Nuclear Data Processing System, Version 2012”, LA-UR-12-27079, Los Alamos National Laboratory, December 2012 (updated for NJOY2012.40, October 2014)

18. R.T. Perry and W.B. Wilson, "Neutron Production from $(\alpha, n)$ Reactions and Spontaneous Fission in ThO2, UO2, and (U,Pu)O2 Fuels," LA-8869-MS, LANL (1981).

19. M.G. Stametalatos and T.R. England, "Accurate Approximations to Average Beta-Particle Energies and Spectra," Nucl. Sci. Eng., 63(2), pp. 204-208.

20. G.K. Schenter and P. Vogel, "A Simple Approximation of the Fermi Function in Nuclear Beta Decay," Nucl. Sci. Eng., 83(3), pp. 393-396.

21. "Measurements of decay heat in spent nuclear fuel at the Swedish interim storage facility, CLAB," ISSN 1402-3091, SKB Rapport R-05-62, Dec. 2006.

22. "ARIANE International Program, Final Report," Belgonucleaire S.A., BN0000253/221-B, Dec. 2000.

23. T. Bahadir and R. Vielma, "Validation of Studsvik CMS For Beznau MOX Cores," Proc. ANFM III, Hilton Head Island, SC, USA, (October 5-8, 2003). 